\title{
Topical propranolol cream in treatment of superficial infantile hemangiomas: a literature review and 4 years of clinical experience
}

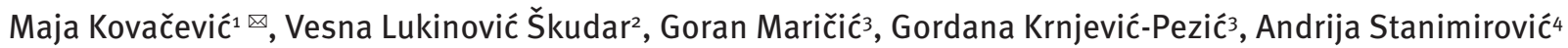

\begin{abstract}
The clinical efficacy and safety profile of propranolol $1 \%$ cream in treatment of superficial infantile hemangiomas (IHs) were determined in a preliminary randomized group of eight infants. Five boys and three girls, 3 to 12 months old, with an IHs superficial capillary type on the forehead, posterior side of the neck, forearm, abdomen, or posterior side of the trunk were examined at our outpatient clinic between 2011 and 2014. Topical propranolol was applied twice daily for 10 months with clinical evaluation and photographic documentation performed every 1 to 2 months. Size, texture, and color changes were monitored. Therapeutic efficacy was evaluated using the Archauer system: Grade I (bad) reduction in size $<25 \%$, Grade II (medium) reduction between $26 \%$ and $50 \%$, Grade III (good) reduction between $51 \%$ and $75 \%$, and Grade IV (excellent) reduction > 75\%. The majority of hemangiomas treated, $62.5 \%$, achieved Grade IV. A Grade III outcome was noticed in one patient with an IH (12.5\%) and Grade II in $25 \%$ of patients with IHs on the abdomen. The treatment was well tolerated without side effects, which indicates that topical application of $1 \%$ propranolol is a safe, effective, and cheap therapeutic option for treating superficial IHs.
\end{abstract}

Keywords: superficial infantile hemangiomas, beta-adrenergic receptor antagonist, propranolol, topical therapy

Received: 13 October 2014 | Returned for modification: 28 October 2014 | Accepted: 10 November 2014

\section{Introduction}

Infantile hemangiomas (IHs), the most common soft-tissue tumors in children with occurrence rates of 8.7 to $12.7 \%$, present in up to $60 \%$ of cases on the head and neck region (1). Lesions occur more frequently in premature infants, females, multiple births, with advanced maternal age, and in Caucasians $(2,3)$. Classification of hemangiomas is based on the layer of skin they affect: superficial or capillary type, deep or cavernous type, and mixed type. Superficial hemangiomas involve the superficial dermis and present as red vascular plaques or nodules. Clinical findings of deep hemangiomas include partially compressible, bluish vascular swellings that involve the deep dermis and subcutis (4). Superficial and deep components are present in mixed hemangiomas. Based on their skin distribution, IHs can also be classified into localized, segmental, indeterminate, and multifocal (5). Localized hemangiomas are restricted to one area, whereas segmental hemangiomas include clusters of lesions that cover a large anatomical area. Multifocal hemangiomas include five or more noncontiguous lesions, often associated with systemic involvement, especially the liver (4).

Infantile hemangiomas appear promptly after birth and pass through two consecutive phases: a proliferative phase, which is most intense in the first 4 to 6 months of life and may last up to 18 months, and an involutional phase (6). Although approximately $90 \%$ of lesions involute by age 9 , incomplete regression is seen in most cases with telangiectatic cutaneous vessels, fibrous fatty tissue, and scar formations (7-10). The rationale for therapy lies in the fact that the prognostic factors for infantile hemangiomas have not yet been elucidated. Development of complications such as visual axis occlusion, airway involvement, ulceration, or permanent disfigurement is related to the anatomical localization of lesions (5). Consequences of uncomplicated infantile hemangio- mas include scarring, disfigurement, or minor functional impairment, which could all have psychosocial consequences on children's lives (11).

For more than 40 years, various forms of corticosteroids, including topical, intralesional, and systemic administration, have been the first-line treatment for IHs $(12,13)$. Pharmacotherapy (corticosteroids, IFN-a, vincristine), cryotherapy, surgery, and laser treatment were standard therapeutic approaches in treating infantile hemangiomas until 2008, when Léauté-Labrèze et al. reported on the clinical efficacy of systemic propranolol in the treatment of infantile capillary hemangiomas (14). After this incidental discovery, the efficacy and safety of nonselective $\beta$-blockers as a therapeutic option for IHs became subjects of numerous studies worldwide, and within the last few years perorally administered propranolol became the gold standard in treatment of IH of all localizations $(11,15,16)$. Advantages of systemic propranolol therapy are rapid onset of action, with good drug tolerability regardless of sex and age at onset of treatment, type of involvement, ulceration, or depth (17-20). Although the complete mechanism of the action of propranolol is not completely understood, explanations lie in possible mechanisms of influence on target endothelial cells: vasoconstriction, inhibition of angiogenesis or vasculogenesis, and induction of apoptosis (21). Vasoconstriction, a consequence of reduction in nitrogen oxide (NO) release, causes the tumor color to fade and the lesion to soften. Propranolol inhibits angiogenesis by down-regulating the RAF mitotic original for activating the protein kinase pathway that leads to decreased expression of VEGF and bFGF, responsible for halting tumor growth. Beta blockers reduce tumor growth by inducing apoptosis in endothelial cells and also by decreasing migration of endothelial progenitor cells $(22,23)$. Itinteang et al. suggested that blockade of $\beta$-receptors may affect tumor involution through regulation of the renin-angiotensin pathway (24). Nevertheless, systemic use of

${ }^{1}$ Croatian Vitiligo Association, Zagreb, Croatia. ${ }^{2}$ School of Medicine, University of Zagreb, Zagreb, Croatia. ${ }^{3}$ Naftalan Special Hospital for Medical Rehabilitation, Ivanić Grad, Croatia. ${ }^{2}$ Department of Clinical Medicine, University of Applied Health Sciences, Zagreb, Croatia. $\bowtie$ Corresponding author: kovacevic.majao1@gmail.com 
propranolol may have side effects such as hypotension, bronchospasm, bradycardia, hypoglycemia, acrocyanosis, gastrointestinal and sleep disturbances, and respiratory infections (25). Because of the possible side effects of systemic propranolol treatment as therapy for IHs, and the intention to adjust this "miracle" therapeutic option for strictly dermatological use, the idea arose to use topical $\beta$-blockers for IHs therapy, especially superficial capillary type IHs (26). The idea for topical treatment of superficial hemangiomas is based on the need to deliver high concentrations of drugs directly to target skin tissues and avoid undesirable systemic effects. Guo and Ni first applied 0.5\% topical timolol solution as a treatment for superficial capillary hemangioma of the eyelid in a 4-month-old infant with very successful results (26). After this report, various studies reported high efficacy of topical timolol gel and solution in treatment of superficial infantile hemangiomas on various anatomical localizations (27-36). Topical propranolol therapy for superficial IHs in concentrations of $1 \%$ to $3 \%$ has recently been suggested $(8,17,21,37)$. Xu et al. applied $1 \%$ propranolol ointment three times a day on 28 lesions in children up to 10 months old; good or partial response was observed in $90 \%$ of IHs without side effects (8). Kunzi-Rapp treated 45 children (from preterm infants to 33 months old) with $65 \mathrm{IH}$ with $1 \%$ propranolol ointment twice daily (17). The best outcome was observed when topical propranolol was administered in the first 6 months of life, with regression in $59 \%$ and growth cessation in $26 \%$ of the hemangiomas. Good therapeutic response was also observed in patients 7 to 33 months old with improvement in all cases. No side effects were noticed regardless of age and lesion size (17). Wang et al. applied 3\% propranolol gel three times a day in 28 patients 28 days to 12 months old with superficial IHs. Reduction in size from $50 \%$ to more than $75 \%$ was observed in 20 patients (21). Niu et al. treated 49 children 1 to 10 months old with 58 superficial IHs with $1 \%$ propranolol ointment; $53.1 \%$ showed good response and $34.7 \%$ partial response (37). Mouhari-Toure et al. reported successful treatment of two superficial IHs in an 11-week-old infant with $2 \%$ propranolol ointment; rapid regression was observed on the 45 th day of treatment with $75 \%$ reduction of the lesions (38). These excellent results encouraged us to estimate the clinical efficacy and safety of $1 \%$ propranolol cream in treatment of superficial infantile hemangiomas in our study group.

\section{Patients and methods}

Diagnosis of the superficial type of hemangioma was made using Waner and Suen's 1999 classification (39). The locations, sizes, and colors of the lesions were documented with clinical photographs. The thickness of the lesions was measured by ultrasound examination. Possible contraindications for applying topical propranolol were excluded by monitoring the heart rate, blood pressure, and blood glucose. Patients 3 to 12 months old without previous treatment interventions were included in this study. Eight patients (five males, three females) with eight super- ficial hemangiomas were treated with $1 \%$ propranolol cream at our outpatient clinic from 2011 to 2014. Propranolol cream was manufactured in collaborative pharmacy practice at a $1 \%$ concentration of propranolol-hydrochloride in a hydrophilic cream. Parents received instructions for applying the cream: twice daily in a thin layer on the surface of the hemangioma. Localization of hemangiomas included the forehead, posterior side of the neck, forearm, abdomen, and posterior side of the trunk. Size, texture, and color changes of the IHs were regularly monitored and photographed at intervals of 1 to 2 months. The therapeutic efficacy was evaluated using the Archauer system: Grade I (bad) reduction in size < 25\%; Grade II (medium) reduction between $26 \%$ and $50 \%$; Grade III (good) reduction between $51 \%$ and $75 \%$; Grade IV (excellent) reduction $>75 \%$ (40).

\section{Results}

Duration of treatment was 10 months. A clinical evaluation and photographic documentation were performed every 1 to 2 months. The outcome of the therapy was evaluated using the Archauer system (40) (Table 1).

Of the eight patients with eight IHs, five treated hemangiomas (62.5\%) achieved a Grade IV success rate with a reduction in the size of the lesion of $>75 \%$ after 7 to 10 months of therapy (Figures 1-5). Improvement between 51 and $75 \%$ (Grade III) was observed in one patient with an IH lesion on the posterior side of the neck after 10 months of treatment. Lesions on the abdomen showed a reduction in size between 26 and 50\% (Grade II).

Topical propranolol 1\% cream was well tolerated, without noticeable side effects (hypotension, bronchospasm, bradycardia, hypoglycemia, acrocyanosis, gastrointestinal and sleep disturbances, or respiratory infections) in any patient.

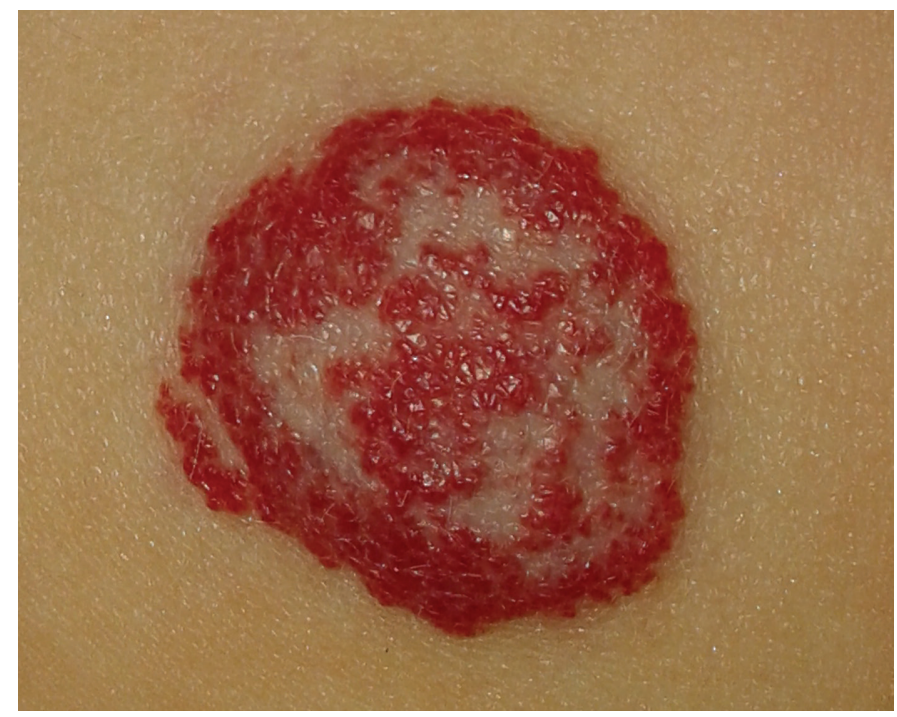

Figure 1 | Superficial infantile hemangioma on the posterior side of the trunk before topical propranolol treatment.

Table 1 | Efficacy of $1 \%$ propranolol cream in different anatomical localizations of superficial infantile hemangiomas.

\begin{tabular}{|c|c|c|c|c|c|}
\hline Localization of superficial IHs & Number of IHs & $\begin{array}{c}\text { Grade I: } \\
\text { improvement }<25 \% \\
(\%)\end{array}$ & $\begin{array}{c}\text { Grade II: } \\
\text { improvement } 26-50 \% \\
(\%)\end{array}$ & $\begin{array}{c}\text { Grade III: } \\
\text { improvement } 51-75 \% \\
(\%)\end{array}$ & $\begin{array}{c}\text { Grade IV: } \\
\text { improvement > 75\% } \\
(\%)\end{array}$ \\
\hline Forehead & 1 & - & - & - & $1(12.5 \%)$ \\
\hline Posterior side of the neck & 2 & - & - & $1(12.5 \%)$ & $1(12.5 \%)$ \\
\hline Forearm & 1 & - & - & - & $1(12.5 \%)$ \\
\hline Abdomen & 2 & - & $2(25 \%)$ & - & - \\
\hline Posterior side of trunk & 2 & - & - & - & $2(25 \%)$ \\
\hline TOTAL & 8 & 0 & $2(25 \%)$ & $1(12.5 \%)$ & $5(62.5 \%)$ \\
\hline
\end{tabular}




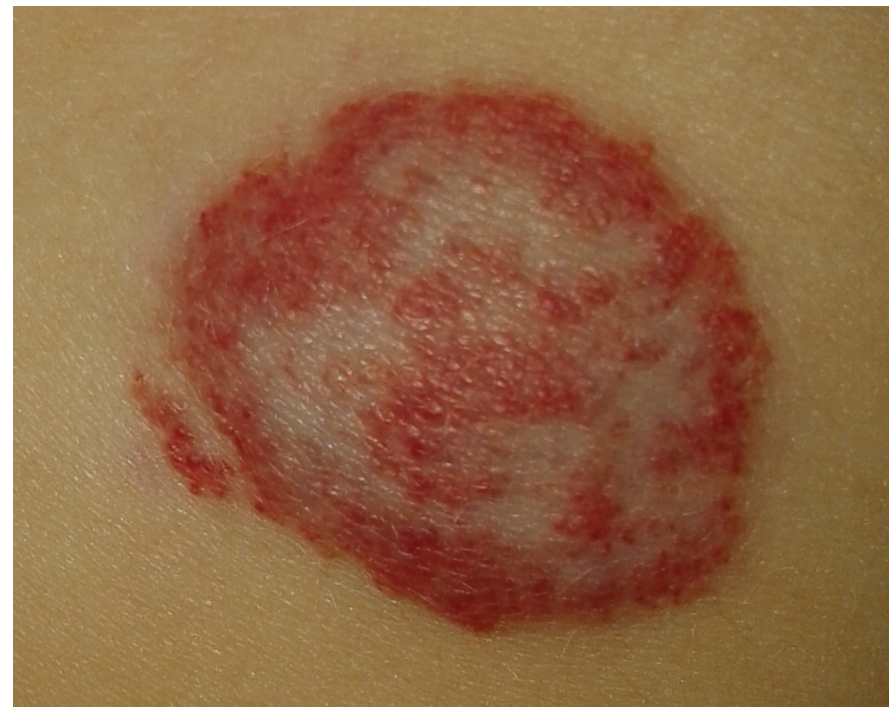

Figure 2 | Superficial infantile hemangioma on the posterior side of the trunk after 1 month treatment with $1 \%$ propranolol cream.

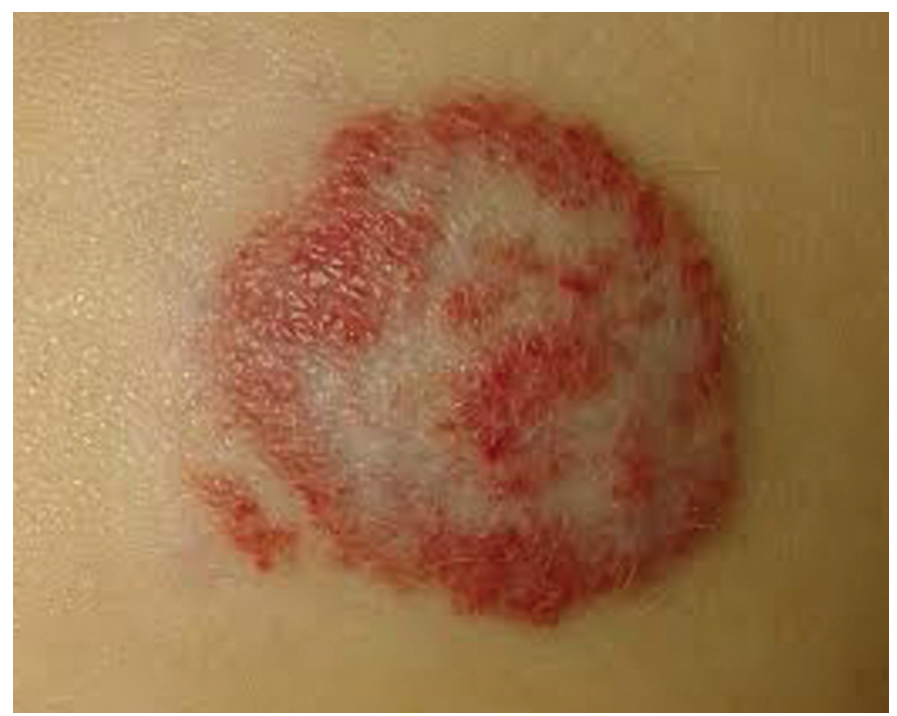

Figure 3 | Superficial infantile hemangioma on the posterior side of the trunk after 3 months treatment with $1 \%$ propranolol cream.

\section{Discussion}

Topical potent corticosteroids and topical imiquimod as part of treatment of IHs have been in use for several years with variable efficacy and several side effects (41-46). Atrophy of the epidermis and hyperpigmentation are common side effects in corticosteroid therapy, whereas undesirable effects of topical imiquimod treatment usually present as ulceration and crusting (41-46). Side effects of effective treatment for IHs with perorally administered propranolol occur in high incidence due to its variable absorption profiles (17). Topical

\section{References}

1. Chang El, Chang El, Thangarajah H, Hamou C, Gurtner GC. Hypoxia, hormones, and endothelial progenitor cells in hemangioma. Lymphat Res Biol. 2007;5:237-43.

2. Frieden IJ, Haggstrom AN, Drolet BA, Mancini AJ, Friedlander SF, Boon L, et al. Infantile hemangiomas: current knowledge, future directions. Proceedings of a research workshop on infantile hemangiomas, April 7-9, 2005, Bethesda, Maryland, USA. Pediatr Dermatol. 2005;22:383-406.

3. Holland KE, Drolet BA. Infantile hemangioma. Pediatr Clin North Am. 2010;57: 1069-83.

4. Sethuraman G, Yenamandra VK, Gupta V. Management of infantile hemangiomas: Current trends. J Cutan Aesthet Surg. 2014;7:75-85.

5. Chiller KG, Passaro D, Frieden IJ. Hemangiomas of infancy: clinical characteristics, morphologic subtypes, and their relationship to race, ethnicity, and sex. Arch Dermatol. 2002;138:1567-76.

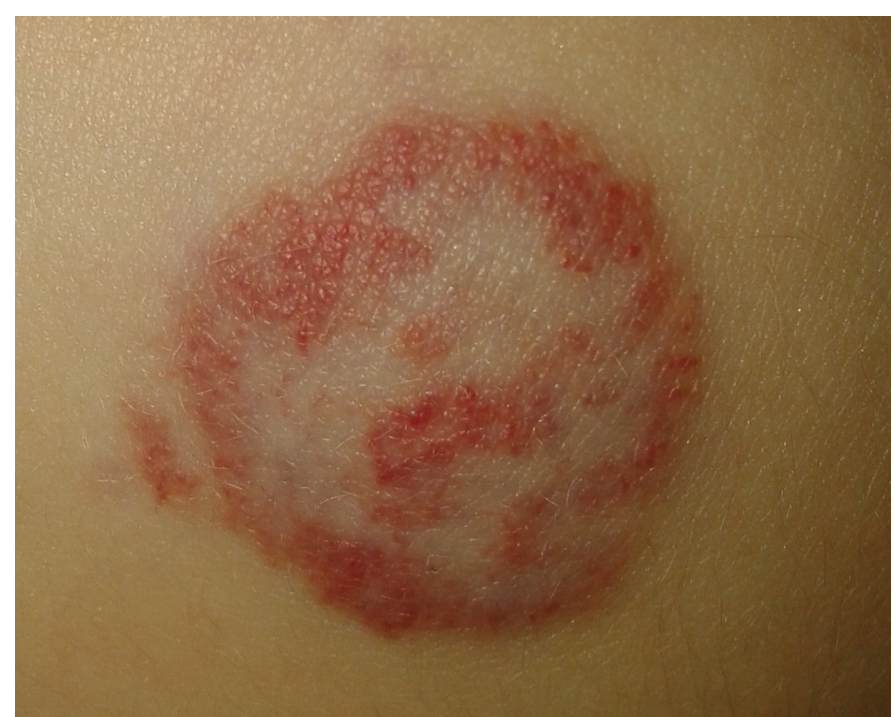

Figure 4 | Superficial infantile hemangioma on the posterior side of the trunk after 5 months treatment with $1 \%$ propranolol cream.

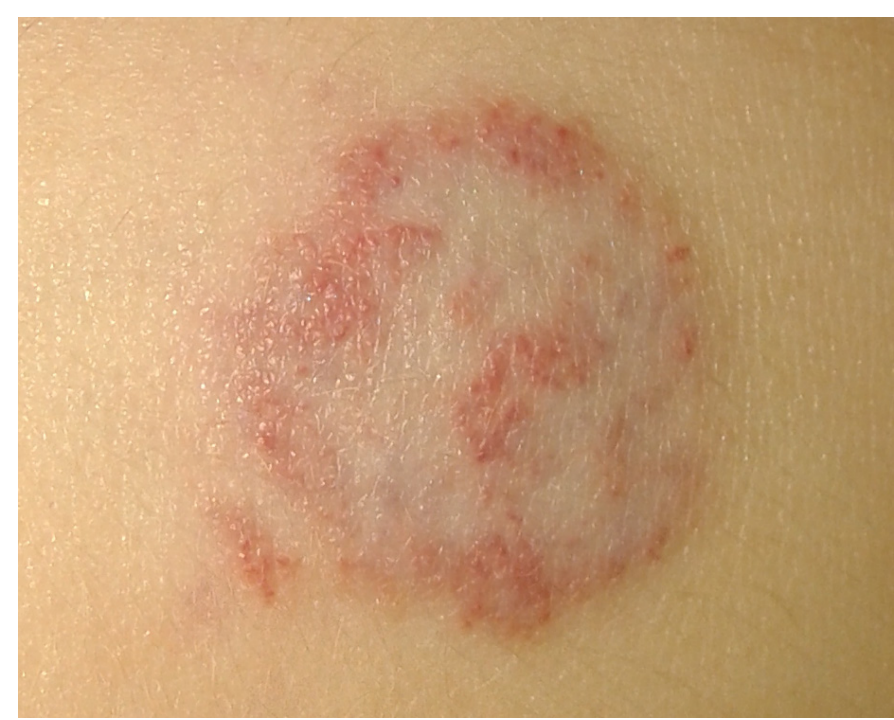

Figure 5 | Superficial infantile hemangioma on the posterior side of the trunk after 7 months treatment with $1 \%$ propranolol cream.

$\beta$-blockers accumulate in the skin in concentrations between $10.4 \%$ and $36.6 \%$ with minimal systemic penetration (4.1-16.1\%) and consequently obtain high efficacy in treatment of IHs without side effects of systemic administration of the drug (47). Our preliminary study suggests that $1 \%$ topical propranolol appears to be safe and effective for treatment of superficial IHs. Further studies are needed to determine the exact concentration of propranolol in the formulation, optimal duration of treatment, and possible inclusion of other $\beta$-adrenergic receptor antagonists in the treatment of superficial IHs.

6. Chang LC, Haggstrom AN, Drolet BA, Baselga E, Chamlin SL, Garzon MC, et al Growth characteristics of infantile hemangiomas: implications for management. Pediatrics. 2008;122:360-7.

7. Margileth AM, Museles M. Cutaneous hemangiomas in children:diagnosis and conservative management. JAMA. 1965;194:523-6.

8. Xu G, Lv R, Zhao Z, Huo R. Topical propranolol for treatment of superficial infantile hemangiomas. J Am Acad Dermatol. 2012;67:1210-3.

9. Eivazi B, Ardelean M, Bäumler W, Berlien HP, Cremer H, Elluru R, et al. Update on hemangiomas and vascular malformations of the head and neck. Eur Arch Otorhinolaryngol. 2009;266:187-97.

10. Werner JA, Dünne AA, Lippert BM, Folz BJ. Optimal treatment of vascular birth marks. Am J Clin Dermatol. 2003;4:745-56. 
11. Léauté-Labrèze C, Prey S, Ezzedine K. Infantile haemangioma: part II. Risks, complications and treatment. J Eur Acad Dermatol Venereol. 2011;25:1254-60.

12. Zarem HA, Edgerton MT. Induced resolution of cavernous hemangiomas following prednisolone therapy. Plast Reconstr Surg. 1967;39:76-83.

13. Cohen SR, Wang $\mathrm{Cl}$. Steroid treatment of hemangioma of the head and neck in children. Ann Otol Rhinol Laryngol. 1972;81:584-90.

14. Léauté-Labrèze C, Dumas de la Roque E, Hubiche T, Boralevi F, Thambo JB, Taïeb A. Propanolol for severe hemangiomas of infancy. N Engl J Med. 2008;358:2649-51.

15. Shah S, Frieden IJ. Treatment of infantile hemangiomas with beta-blockers: a review. Skin Therapy Lett. 2013;18:5-7.

16. Chantasart D, Hao J, Li SK. Evaluation of skin permeation of $\beta$-blockers for topical drug delivery. Pharm Res. 2013;30:866-77.

17. Kunzi-Rapp K. Topical propranolol therapy for infantile hemangiomas. Pediatr Dermatol. 2012;29:154-9.

18. Hermans DJ, van Beynum IM, Schultze Kool LJ, van de Kerkhof PC, Wijnen MH, van der Vleuten CJ. Propranolol, a very promising treatment for ulceration in infantile hemangiomas; a study of 20 cases with matched historical controls. J Am Acad Dermatol. 2011;64:833-8.

19. Saint-Jean $M$, Léauté-Labrèze $C$, Mazereeuw-Hautier J, Bodak N, Hamel-Teillac D, Kupfer-Bessaguet I, et al; Groupe de Recherche Clinique en Dermatologie Pédiatrique. Propranolol for treatment of ulcerated infantile hemangiomas. J Am Acad Dermatol. 2011;64:827-32.

20. Bagazgoitia L, Torrelo A, Gutiérrez JC, Hernández-Martín A, Luna P, Gutiérrez M, et al. Propranolol for infantile hemangiomas. Pediatr Dermatol. 2011;28:108-14.

21. Wang L, Xia Y, Zhai Y, Li C, Li Y. Topical propranolol hydrochloride gel for superficial infantile hemangiomas. J Huazhong Univ Sci Technolog Med Sci. 2012;32:923-6.

22. Sommers Smith SK, Smith DM. Beta blockade induces apoptosis in cultured capillary endothelial cells. In Vitro Cell Dev Biol Anim. 2002;38:298-304.

23. Stiles J, Amaya C, Pham R, Rowntree RK, Lacaze M, Mulne A, et al. Propranolol treatment of infantile hemangioma endothelial cells: a molecular analysis. Exp Ther Med. 2012;4:594-604.

24. Itinteang T, Brasch HD, Tan ST, Day DJ. Expression of components of the rennin angiotensin system in proliferating infantile haemangioma may account for the propranolol-induced accelerated involution. J Plast Reconstr Aesthet Surg. 2011;64:759-65.

25. Marqueling AL, Oza V, Frieden IJ, Puttgen KB. Propranolol and infantile hemangiomas four years later: a systematic review. Pediatr Dermatol. 2013;30:182-91.

26. Guo S, Ni N. Topical treatment for capillary hemangioma of the eyelid using beta-blocker solution. Arch Ophthalmol. 2010;128:255-6.

27. Semkova K, Kazandjieva J. Rapid complete regression of an early infantile hemangioma with topical timolol gel. Int I Dermatol. 2014:53:241-2.

28. Pope E, Chakkittakandiyil A. Topical timolol gel for infantile hemangiomas: a pilot study. Arch Dermatol. 2010;146:564-5.

29. Xue K, Hildebrand GD. Deep periocular infantile capillary hemangiomas responding to topical application of timolol maleate, $0.5 \%$, drops. JAMA Ophthalmol. 2013;131:1246-8.

30. Xue K, Hildebrand GD. Topical timolol maleate $0.5 \%$ for infantile capillary haemangioma of the eyelid. Br J Ophthalmol. 2012;96:1536-7.
31. Merino-Bohórquez V, Casas M, Caracuel F, Cameán M, Fernández-Anguita MJ, Ramírez-Soto G, et al. Physicochemical stability of a new topical timolol $0.5 \%$ gel formulation for the treatment of infant hemangioma. Pharm Dev Technol. 2014 Jul 22:1-8. [Epub ahead of print]

32. Ni N, Langer P, Wagner R, Guo S. Topical timolol for periocularhemangioma: report of further study. Arch Ophthalmol. 2011;129:377-9.

33. Rizvi SA, Yusuf F, Sharma R, Rizvi SW. Management of superficial infantile capillary hemangiomas with topical timolol maleate solution. Semin Ophthalmol. 2013 Sep 27. [Epub ahead of print]

34. Yu L, Li S, Su B, Liu Z, Fang J, Zhu L, et al. Treatment of superficial infantile hemangiomas with timolol: Evaluation of short-term efficacy and safety in infants. Exp Ther Med. 2013;6:388-90.

35. Thomas J, Kumar P, Kumar DD. Ulcerated infantile haemangioma of buttock successfully treated with topical timolol. J Cutan Aesthet Surg. 2013;6:168-9.

36. Ciudad Blanco C, Campos Domínguez M, Moreno García B, Villanueva ÁlvarezSantullano CA, Berenguer Fröhner B, Suárez Fernández R. Episcleral infantile hemangioma successfully treated with topical timolol. Dermatol Ther. 2014. doi: $10.1111 / \mathrm{dth} .12173$.

37. Niu JN, Xu GQ, Lü RR, Huo R. [Treatment of superficial infantile hemangiomas with topical propranolol]. Zhonghua Zheng Xing Wai Ke Za Zhi. 2013;29:100-3. Chinese.

38. Mouhari-Toure A, Azoumah KD, Tchamdja K, Saka B, Kombaté K, Tchangaï-Walla $\mathrm{K}$, et al. [Rapid regression of infantile haemangioma with $2 \%$ propranolol ointment]. Ann Dermatol Venereol. 2013;140:462-4. French.

39. Waner M, Suen JY, eds. Hemangiomas and vascular malformations of the head and neck. New York: Wiley-Liss; 1999.

40. Achauer BM, Chang C), Vander Kam VM. Management of hemangioma of infancy: review of 245 patients. Plast Reconstr Surg. 1997;99:1301-8.

41. Ranchod TM, Frieden IJ, Fredrick DR. Corticosteroid treatment of periorbital haemangioma of infancy: a review of the evidence. Br J Ophthalmol. 2005;89:1134-8.

42. Pandey A, Gangopadhyay AN, Sharma SP, Kumar V, Gupta DK, Gopal SC. Evaluation of topical steroids in the treatment of superficial hemangioma. Skinmed. 2010;8:9-11.

43. Qiu Y, Ma G, Lin X, Jin Y, Chen H, Hu X. Treating protruding infantile hemangiomas with topical imiquimod $5 \%$ cream caused severe local reactions and disfig. uring scars. Pediatr Dermatol. 2013;30:342-7.

44. Qiu Y, Ma G, Yang J, Hu X, Chen H, Jin Y, et al. Imiquimod $5 \%$ cream versus timolol $0.5 \%$ ophthalmic solution for treating superficial proliferating infantile haemangiomas: a retrospective study. Clin Exp Dermatol. 2013;38:845-50.

45. Jiang C, Hu X, Ma G, Chen D, Jin Y, Chen H, et al. A prospective self-controlled phase II study of imiquimod $5 \%$ cream in the treatment of infantile hemangioma. Pediatr Dermatol. 2011;28:259-66.

46. Barry RB, Hughes BR, Cook LJ. Involution of infantile haemangiomas after imiquimod 5\% cream. Clin Exp Dermatol. 2008;33:446-9.

47. Ademola JI, Chow CA, Wester RC, Maibach HI. Metabolism of propranolol during percutaneous absorption in human skin. J Pharm Sci. 1993;82:767-70. 